\title{
OBTENÇÃO DE BEBIDA A PARTIR DE SUCO DE CAJU (Anacardium occidentale, L.) E EXTRATO DE GUARANÁ (Paullinia cupana sorbilis Mart. Ducke) ${ }^{1}$
}

\author{
LILIANA COSTA SOARES²; GERARDO SÉRGIO FRANCELINO DE OLIVEIRA ${ }^{3}$; \\ GERALDO ARRAES MAIA3 ; JOSÉ CARLOS SABINO MONTEIRO ${ }^{3}$ e ANTENOR SILVA JUNIOR ${ }^{3}$.
}

\begin{abstract}
RESUMO - A partir do extrato de semente de guaraná com 0,96\% de cafeína, foram testadas várias formulações para obtenção de uma bebida, utilizando-se de suco de caju clarificado e concentrado, caramelo, aromatizantes artificiais de caju e guaraná e acidulante, tendo também como variável os diversos graus de doçura ( ${ }^{\circ}$ Brix). As melhores formulações foram selecionadas de acordo com os resultados da avaliação sensorial, onde se utilizou o teste de ordenação. A formulação selecionada foi processada e envasada em embalagens de vidro. Para determinar a aceitabilidade, o produto final foi submetido a análises físico-químicas e sensoriais.
\end{abstract}

Palavras-chave: formulação bebida, semente de guaraná, suco de caju clarificado concentrado.

\section{OBTENTION OF DRINK FROM CASHEW APPLE JUICE (Anacardium occidentale, L.) AND GUARANA EXTRACT (Paullinia cupana sorbilis Mart. Ducke)}

\begin{abstract}
From Guaraná seeds extract with $0,96 \%$ caffein content several formulations were evaluated in order to obtain a beverage using clarified cashew juice concentrate, caramel and guaraná artificial flavors and acidulant, using several sweetness grade a variable. The best formulations were selected according to sensorial evaluation results, using the ordenation test. The selected product ( $14^{\circ}$ Brix formulation) was manufactured and filled in glass bottles. In order to determine the acceptability the final product was submited to physical chemical and sensorial analysis.
\end{abstract}

Key words: Guaraná seeds, concentrated cashew apple juice, beverage formulation.

\section{INTRODUÇÃO}

As bebidas não alcoólicas têm largo consumo no mundo inteiro. Em todos os países, os levantamentos estatísticos revelam números crescentes de consumo, tanto per capita quanto global. Esses valores são mais expressivos quando se referem a bebidas obtidas de as frutas, pelo fato de as mesmas se constituírem fontes fundamentais de vitaminas e minerais para a dieta humana, além de seus atrativos sabores.

No Ceará, particularmente, vale a pena considerar o imenso potencial da cultura do caju, pois o suco obtido deste, considerando seu alto valor nutritivo, representa uma matériaprima de excelentes perspectivas para a elaboração de novas bebidas.

Com relação ao guaraná propriamente dito, a disponibilidade de matéria-prima é grande, porém nem sempre se pode assegurar a qualidade, visto que grande parte da produção é obtida de plantas nativas, podendo o abastecimento ficar prejudicado. É recomendado, portanto, o plantio de forma racional, para assegurar a produção necessária à indústria (Tocchini, 1989).

O setor de bebidas evoluiu com sua segmentação em bebidas esportivas, chá gelado, bebidas nutricionais, funcionais e sucos de frutas.

Objetivou-se, portanto, neste trabalho, o desenvolvimento de uma bebida formulada com suco de caju clarificado e concentrado e extrato de guaraná que, além de vir atender às exigências do mercado consumidor, diversificando suas opções alimentares, contribua para a melhoria do nível de saúde da população.

\section{MATERIAL E MÉTODOS}

As sementes de guaraná e o suco de caju clarificado e concentrado foram fornecidos por indústrias locais, adequadamente acondicionados e em quantidades suficientes à demanda do experimento.

As sementes de guaraná, ao chegarem ao local de processamento, foram separadas da película que as envolve com ajuda de pilões e fricção manual. Depois, a amêndoa foi moída, obtendo-se um pó com granulometria de $1,25 \mathrm{~mm}$. Com a amêndoa em pó, efetuou-se a extração em solução alcoólica a $47 \%$, na proporção em peso de duas partes de solvente para uma parte de soluto. A mistura foi agitada e deixada em infusão por 24 horas. Decorrido o tempo de infusão, separou-se a solução por filtração, lavando-se o material retido no filtro com o solvente quente $\left(70^{\circ} \mathrm{C}\right)$. A mistura foi submetida a um aquecimento em banho-maria à temperatura de $\left(70^{\circ} \mathrm{C}\right)$, onde o álcool foi evaporado. $\mathrm{O}$ extrato obtido foi acondicionado em garrafas de vidro âmbar de 1 litro, que foram fechadas com tampa de rosca. As embalagens contendo o extrato foram armazenadas sob

1 Trabalho $\mathrm{n}^{\circ}$ 128/2000. Recebido: 05/07/2000. Aceito para publicação: 17/04/2001.

2 Bolsista da Capes.

3 Departamento de Tecnologia de Alimentos/UFC Cx. Postal 12168, Fortaleza-Ceará, Brasil. 
refrigeração, para uso posterior na formulação da bebida.

As seguintes determinações físico-químicas foram efetuadas no suco de caju clarificado concentrado e diluído, no extrato de guaraná e na bebida funcional: $\mathrm{pH}$ em potenciômetro DIGIMED modelo DMPH-2; sólidos solúveis ( $\left.{ }^{\circ} \mathrm{Brix}\right) \mathrm{em}$ refratômetro marca AUS JENA modelo I; acidez total, açúcares totais, açúcares não redutores e açúcares redutores de acordo com técnicas descritas pelo INSTITUTO ADOLFO LUTZ (1985); tanino foi determinado segundo a descrição feita no A.O.A.C. (1975); cafeína foi determinada pelo método recomendado por Pearson (1971) e vitamina C através do método recomendado por Pearson \& Cox (1976).

Com o objetivo de se obter uma bebida com formulação aceitável pelo consumidor, realizou-se uma série de préexperimentos, levando-se em conta o ponto de equilíbrio entre os seus componentes e também os parâmetros grau de doçura, aroma, acidez e sabor. A bebida escolhida, através de testes sensoriais, foi novamente formulada, tendo somente como variável seu grau de doçura. Por fim, a que apresentou melhor resultado na análise de degustação foi usada, conforme processo detalhado no fluxograma (Figura 1).

Para a obtenção de 13 L de bebida, utilizou-se a seguinte formulação: extrato de guaraná $-260 \mathrm{ml}$, suco de caju- $2080 \mathrm{ml}$, água- $10660 \mathrm{ml}$, benzoato de sódio-6,5 g e sorbato de potássio$6,5 \mathrm{~g}$, perfazendo um total de $13 \mathrm{~g}$ e ácido cítrico-7,5 g. A bebida sofreu um tratamento térmico à temperatura de $90^{\circ} \mathrm{C}$ por 30 segundos, suficiente para se obter esterilização comercial e também inativar a ação indesejável de enzimas, que afetam a cor, turbidez, sabor e corpo da bebida (Gava, 1985; Cipola, 1986).

Em seguida, a bebida foi acondicionada, ainda quente, em garrafas de $250 \mathrm{ml}$, sendo imediatamente fechadas com tampa de rosca. O produto foi então resfriado rapidamente em uma unidade de resfriamento, sofrendo um choque térmico, com a finalidade de se evitar que microrganismos termófilos sobrevivessem e posteriormente viessem a deteriorar a bebida (Soares, 1986).

A armazenagem ocorreu por um período variável, em média não inferior a três meses, sob condições de temperatura ambiente $\left(27^{\circ} \mathrm{C}\right)$.

A avaliação sensorial foi realizada com o objetivo de se determinar a preferência e a aceitabilidade da bebida por prováveis consumidores. Na análise sensorial de preferência dos 19 pré-experimentos e das 4 formulações, com variação apenas no ${ }^{\circ}$ Brix, utilizaram-se os testes de ordenação e de escala hedônica e, para análise dos dados obtidos, fez-se uso do teste de Friedman, segundo Moraes (1978).

$\mathrm{Na}$ avaliação da aceitabilidade da bebida funcional, foi utilizada a escala hedônica, com 100 provadores, segundo as recomendações do "Sensory Evaluation Division of the Institute of Food Technologists" (Morales, 1994). Este método permite quantificar a intensidade de opinião de cada provador em relação a um atributo específico.

Foi utilizado um grupo de provadores constituído por 100 atletas, 68 homens e 32 mulheres, da Academia de Ginástica Pódium, com idade variando de 18 a 45 anos, e as amostras foram colocadas em copos descartáveis de $50 \mathrm{ml}$ de capacidade, com temperatura entre $16^{\circ} \mathrm{C}$ e $18^{\circ} \mathrm{C}$ e servidas pela manhã entre 9 e 11 horas, e à tarde entre 15 e 17 horas.

\section{RESULTADOS E DISCUSSÃO}

A Tabela 1 apresenta os resultados das determinações físico-químicas e químicas realizadas no suco de caju clarificado concentrado e diluído utilizado para a obtenção da bebida mista. Observa-se que o valor do $\mathrm{pH} 4,28$ é semelhante aos resultados obtidos por Tochinni \& Lara (1979), que foi de 4,0 para o suco simples, e entre 4,0 e 4,1 para os sucos concentrados. O teor de sólidos solúveis do suco clarificado concentrado e diluído foi de $14^{\circ}$ Brix.

O teor de tanino encontrado $(0,32 \%)$ compara-se ao resultado obtido por Price et al. (1974), que afirmam ter o suco de caju alto teor de tanino $(0,4 \%)$, que lhe confere um efeito adstringente.

Para a vitamina $\mathrm{C}$, na amostra em estudo, obeteve-se uma média de 0,264\% (264mg/100g), sendo diretamente comparável à faixa encontrada por Leme Junior (1951), 181 a 229 mg/100g; por Soares \& Maia (1970), 151 a 387 mg/100g; Trevas Filho (1971), 120,8 a 231,2 mg/100g.

Pruthi et al. (1963) verificaram que a retenção do ácido ascórbico era ligeiramente melhor no suco não clarificado concentrado $(827,50 \mathrm{mg} / 100 \mathrm{~g})$, do que no clarificado concentrado $(824,00 \mathrm{mg} / 100 \mathrm{~g})$, embora o clarificado produzisse um concentrado de melhor cor e sabor.

O percentual de açúcares redutores encontrado na bebida foi de $12,09 \%$. Já os açúcares não redutores não se apresentaram em teores significativos e, segundo Desrosier (1963), durante o processamento, a solução de sacarose na presença de ácido sofre uma hidrólise, na qual açúcares invertidos são formados, sendo a taxa de inversão dependente da temperatura, do tempo de aquecimento e do valor do $\mathrm{pH}$ da solução.

A acidez titulável determinada em percentagem de ácido cítrico $(0,35 \%)$ está de acordo com o encontrado por Pruthi et al. (1963), que foi de 0,30\% para suco clarificado antes da concentração e está abaixo do obtido para suco clarificado concentrado $(1,6 \%)$.

Os resultados obtidos para as análises efetuadas no extrato de guaraná são apresentados na Tabela 2 .

A amêndoa da semente de guaraná, descascada e separada da casca, contém uma substância cerosa que dificilmente permite extratos límpidos e, quando estes são conseguidos, após a remoção da cera, os polifenóis que passam em solução nos extratos, e aos quais se deve a cor dos mesmos, se polimerizam, formando suspensão fina e turvando os extratos (Maravalhas, 1965).

A eficiência da extração ficou em torno de $42,50 \%$ e pode ser considerada boa. A avaliação foi realizada mediante a comparação do teor de cafeína $(0,96 \%)$ obtido no extrato com o resultado da caracterização química da amêndoa $(2,26 \%)$ da semente de guaraná utilizada.

Ao se comparar o teor médio de tanino encontrado $(9,1 \%)$ com os obtidos em vários extratos $(4,08 \%)(1,22 \%)(1,25)$ $(1,845)$ por Tocchini $(1977)$, observou-se que o mesmo se encontra bastante elevado. Possivelmente, esses extratos se encontram em concentrações mais baixas, em conseqüência de processos empregados com a finalidade de reduzir o teor de tanino, pois este tende a causar o surgimento de turbidez e de amargor e/ou adstringência no produto final.

Hulme (1970) cita que alguns flavonóides, em grandes 
doses, agem como antioxidantes, protegendo o ácido ascórbico. Portanto, a presença do elevado teor de tanino no extrato de guaraná pode ter grande importância na conservação da vitamina C.

O teor de sólidos solúveis determinado foi de $1,5^{\circ} \mathrm{Brix}$, sendo este valor esperado, pois as sementes, de um modo geral, são pobres em carboidratos solúveis.

A Tabela 3 apresenta os resultados das determinações físico-químicas e químicas realizadas na bebida obtida.

A bebida processada apresentou cor amarelo-âmbar, resultante do processo de caramelização dos açúcares do suco de caju que, além de sua comprovada riqueza em vitaminas e sais minerais, apresenta excelente sabor e propriedades refrescantes, quando consumida gelada.

Com o objetivo de se definir a formulação ideal da bebida, foram realizados 19 pré-experimentos, com combinações e concentrações diferentes, de suco de caju e extrato de guaraná. Nas condições de formulação, os tratamentos propostos foram considerados eficientes para garantir padrões de qualidade do produto elaborado.

Os métodos sensoriais de preferência e aceitação são muito aplicados, pois medem a opinião de consumidores, e têm por objetivo determinar a vendabilidade de bons produtos (Moraes, 1978).

O resultado estatístico da avaliação sensorial para a seleção da melhor formulação da bebida, variando somente o grau de doçura, encontra-se abaixo.

\section{Resultado do teste de Friedman}

Neste experimento, o número de amostras foi $\mathrm{k}=4$, o número de blocos(provadores), $\mathrm{b}=30$ e $\mathrm{K}=4,3$.

A estatística $\mathrm{K}$ segue uma distribuição quiquadrada, com k-1 graus de liberdade, cujo valor tabelado é:

$$
\mathrm{X}_{3 \mathrm{gl}}^{2}=7,815 \text {, com } \alpha=5 \%
$$

Como $X^{2}$ calculando $(4,3)<X^{2}$ tabelado $(7,815)$, aceitamos $\mathrm{H}_{\mathrm{o}}$, isto implica dizer que o teste não foi significativo ao nível de $5 \%$ de probabilidade $(\mathrm{P}>0,05)$, possuindo as amostras o mesmo grau de preferência para os provadores.

Como o teste de Friedman não foi significativo, verificouse novamente qual foi a bebida preferida através do percentual de provadores que atribuíram notas menores ou igual a $2 \mathrm{e}$ maiores ou igual a 3 . A formulação que obteve maior número de notas 1 e 2 , foi considerada a preferida.

Com base nos resultados da análise, conclui-se que a preferência dos degustadores foi para a bebida com $14^{\circ} \mathrm{Brix}$, pois esta obteve o maior percentual de preferência $(53,3 \%)$, associado ao menor percentual de rejeição $(13,3 \%)$.

A formulação escolhida sensorialmente demonstrou um alto índice de aceitação entre atletas, principal público-alvo do produto, pois obteve aceitabilidade absoluta (de gostei muito a muitíssimo).

\section{CONCLUSÕES}

1 - A simples adição do extrato à bebida, por si só, não proporciona o aroma típico esperado do guaraná, sendo aqui o importante o efeito estimulante da cafeína.

2 - A utilização do suco de caju clarificado e concentrado é
FIGURA 1 - Fluxograma das operações seguidas para obtenção da bebida funcional.

FORMULAÇÃO

$\downarrow$

$$
\text { A GIT A ÇÃ O }
$$

$\downarrow$

TRATAMENTO TÉRMICO

$\downarrow$

ENCHIMENTO A QUENTE

(HOT FILL)

$\downarrow$

FECHAMENTO

$\downarrow$

RESFRIAMENTO

$\downarrow$

ARMAZENAGEM

TABELA 1- Caracterização química e físico-química do suco de caju clarificado concentrado e diluído a $14^{\circ}$ Brix.

\begin{tabular}{lc}
\hline Determinações & Teor médio \\
\hline Tanino (\% de ácido tânico) & 0,32 \\
PH & 4,28 \\
Sólidos solúveis ( ${ }^{\circ}$ Brix) & 14,00 \\
Açúcares redutores (\%) & 12,09 \\
Açúcares não redutores (\%) & traços \\
Acidez (\% de ácido cítrico) & 0,35 \\
Vitamina C (\%) & 0,264 \\
\hline
\end{tabular}

TABELA 2 - Caracterização química e físico-química do extrato de guaraná.

\begin{tabular}{ll}
\hline Determinações & Teor médio \\
\hline PH & 5,63 \\
Sólidos solúveis ( ${ }^{\circ}$ Brix) & 1,50 \\
Tanino (\% de ácido tânico) & 9,10 \\
Cafeína (\%) & 0,96 \\
\hline
\end{tabular}


TABELA 3 - Caracterização química e físico-química da bebida funcional de melhor aceitabilidade.

\begin{tabular}{lc}
\hline Determinações & Teor médio \\
\hline PH & 4,37 \\
Sólidos solúveis ( ${ }^{\circ}$ Brix) & 14,00 \\
Acidez (\% de ácido cítrico) & 0,38 \\
Vitamina C (\%) & 0,216 \\
Açúcares redutores (\%) & 13,08 \\
Açúcares não redutores (\%) & traços \\
Açúcares totais & 13,08 \\
Tatino (\% de ácido tânico) & 0,39 \\
Cafeína & 0,02 \\
\hline
\end{tabular}

bastante viável como matéria-prima para este tipo de bebida dentro do processo tecnológico utilizado.

3. A bebida formulada a partir de suco de caju e extrato de guaraná, teve boa aceitabilidade pelos provadores, tornando-se uma importante opção para o consumidor.

\section{REFERÊNCIAS BIBLIOGRÁFICAS}

ASSOCIATION OF OFFICIAL ANALYTICAL CHEMISTS. Official methods of analysis of the Association of Official Analytical Chemists. 2.ed. Washington,1975.

CIPOLA, L. E. Produção de sucos para envasamento asséptico. Revista de Alimentos e Tecnologia. São Paulo, n.8, p.14, mar./ abr. 1986.

DESROSIER, N. W. The technology of food preservation. West port: AVI, 1963. 405p.

GAVA, A. J. Processamento asséptico de sucos de frutas. Revista de Alimentação. São Paulo, n.76, p.32-37, jan./fev., 1985.

HULME, A. C. The biochemistry of fruit and their products. London: Academic Press, 1970. v.1.

INSTITUTO ADOLFO LUTZ. Métodos químicos e físicos para análise de alimentos. Normas Analíticas do Instituto Adolfo Lutz. 3.ed. São Paulo:1985. v.1, 533p.

LEME JÚNIOR, J. A vitamina $\mathrm{C}$ em algumas plantas brasileiras e exóticas. Revista Agricultura, Piracicaba, v. 26, n.9/10, p. 319-30, 1951.
MARAVALHAS, N. Casca de guaraná - matéria-prima para cafeína - método industrial de extração. In: Estudos sobre o guaraná e outras plantas produtoras de cafeína. Manaus: Instituto Nacional de Pesquisas da Amazônia, 1965. p.5-11. (INPA. QUÍMICA, n. 10).

MORAES, M. A. C. Métodos para avaliação sensorial de alimentos. Campinas: UNICAMP, 1978. 87p.

MORALES, A. La evaluatión sensorial de los alimentos en la teoria y la prática. Zaragoza, Espanha: Acribia, 1994. 198p.

PEARSON, D. The chemical analysis of foods. 6.ed. New York, Chemical Publ., 1971. 604p.

PEARSON, D.; COX, H. E. The chemical analysis of foods. New York: Chemical Publ. 1976.

PRICE, R. L.; HOLANDA, L. F. F.; MOURA FÉ, J. de A. Industrialização of cashew. Progressive Agriculture in Arizona, v. 26, n. 2, p. 13-16, mar./apr., 1974.

PRUTHI, J. S.; CHAHRABORTY, N. R.; SONDHI, S. P.; SASTRY, L.V. L. Studies on concentrating the juice of the cashew apple (Anacardium occidentale, L.). Food Tecnology, Chicago, v. 17, n. 11, p. $95-98.1963$.

SOARES, J. B. O caju: aspectos tenológicos. Fortaleza: BNB, 1986. 256.

SOARES, J. B.; MAIA, G. A. Determinação colorimétrica de ácido ascórbico em alguns frutos regionais. Pesquisa Agropecuária do Nordeste, Recife, v. 2, n. 2, p. 79-81, jun./dez. 1970. Apud:LIMA(1988).

TREVAS FILHO, V. Tecnologia de produtos do pedúnculo do caju. Fortaleza, I SEMANA DO CAJU, 1971. 101p. Apud: BERNHARDT \& HASHIZUME (1978).

TOCCHINI, R. P. Alguns aspectos sobre o guaraná (Paullinia cupana var. sorbilis Ducke) e sua ralação com o refrigerante de guaraná. Boletim Instituto Tecnológico de Alimentício, Campinas, n.54, p.41-54, nov./dez. 1977.

TOCCHINI, R. P.; LARA, J. C. C. Estudos preliminares da concentração do suco de caju. Boletim do ITAL, Campinas, v. 16, n. 4, p. 413-420. 1979.

TOCCHINI, R. P. Processamento e obtenção de produtos do guaraná. Bol. SBCTA (Sociedade Brasileira de Ciência e Tecnologia de Alimentos), Campinas, v.23, n.1/2, p.90-95, 1989. 